Final-Draft - The original publication is available at www.springer-link.com

\title{
Plasma-Facing Materials for Fusion Devices ${ }^{1}$
}

\author{
Rainer Behrisch \\ Max Planck-Institut für Plasmaphysik, EURATOM Association, Garching, Germany \\ Received February 2, 2010
}

\begin{abstract}
In a future D/T fusion reactor the walls of the vessel containing the magnetically confined hot plasma have to stand simultaneously very high power, particle and neutron loads. In today's high temperature plasma experiments at the areas of the highest load, i.e. the divertor and the limiters, W, Mo and Carbon (CFC) are used and Be, W, Mo, Inconel and stainless steel are at the other wall areas. These materials are also envisaged for future bigger fusion experiments, such as ITER [1-3]. The resistance of these materials to the different expected higher loads in a fusion reactor is only partly known and more investigations are needed with respect to find better materials and/or a modification of the divertor.
\end{abstract}

DOI: $10.1134 / \mathrm{S} 1027451010040014$

\section{INTRODUCTION, BACKGROUND}

Our sun and the stars get the energy, which they radiate into the universe, by nuclear fusion of Hydrogen atoms to Helium atoms [4]. Since about 60 years there is a big international research effort in exploring the possibilities for also using this energy by controlled fusion of hydrogen atoms to $\mathrm{He}$ on our planet [5]. There are several possible fusion reactions [6] but the reaction with the largest cross section at the lowest energy is the reaction:

$$
\mathrm{D}+\mathrm{T} \longrightarrow{ }^{4} \mathrm{He}(3.5 \mathrm{MeV})+n(14.1 \mathrm{MeV}) \text {. }
$$

In order to initiate the fusion reactions the $\mathrm{D}$, $\mathrm{T}$ gas has to be heated to a temperature of about 100 Million $\mathrm{K}$ or about $12 \mathrm{keV}$, at a density of about $n=10^{14} \mathrm{~cm}^{-3}$ [7]. At this temperature the gas is in the plasma state. In the stars the hot plasma is confined by gravity but this is negligible for the small amounts of plasma on our planet. Here it is successfully tried to magnetically confine the hot plasma. The major emphasis in fusion research has been up to now on confining and heating a hydrogen plasma within closed nested magnetic surfaces in a toroidal vessel, such as in a tokamak (Fig. 1) [8-12] or a stellarator (Fig. 2) [13-25]. The vessel walls have to protect the hot plasma from the atmospheric environment and the magnetic field reduces the plasma load to the inside of the vessel walls, while the neutrons leave the plasma and impinge nearly uniformly distributed onto the vessel walls.

In the tokamak the magnetic surfaces for plasma confinement are created firstly by external coils which produce a high toroidal magnetic field. For creating the closed nested magnetic surfaces a poloidal magnetic field is superimposed being created by a toroidal electric current $I_{\mathrm{p}}$ in the plasma column. This current also heats the plasma. It is driven and controlled by a toroidal electric field, which is induced by a magnetic flux variation in the torus centre $[8,12]$. Due to the natural time limit for the magnetic flux variation and thus the current induced in the plasma, tokamaks operate generally only for short times, i.e. in pulses. The current may, however, be driven further by additional means, such as a "Bootstrap current", which is initiated by the pressure gradient between the plasma centre and the outer plasma $[20,22,26]$ or by tangential injection of intense neutral hydrogen beams and/or by inducing fast electromagnetic waves in the plasma [21, 27-29]. In present experiments the main toroidal magnetic field $B_{\mathrm{t}}$ is in the range between 5 and $10 \mathrm{~T}$ and the plasma current $I_{\mathrm{p}}$ is of the order of 0.1 to 10 MA.

Due to instabilities of the distribution of the current in the plasma [30-31], such as by changes in the plasma position or of the electric resistance of the plasma, caused by an uncontrolled density increase $[25,32]$, such as the influx of impurity atoms released

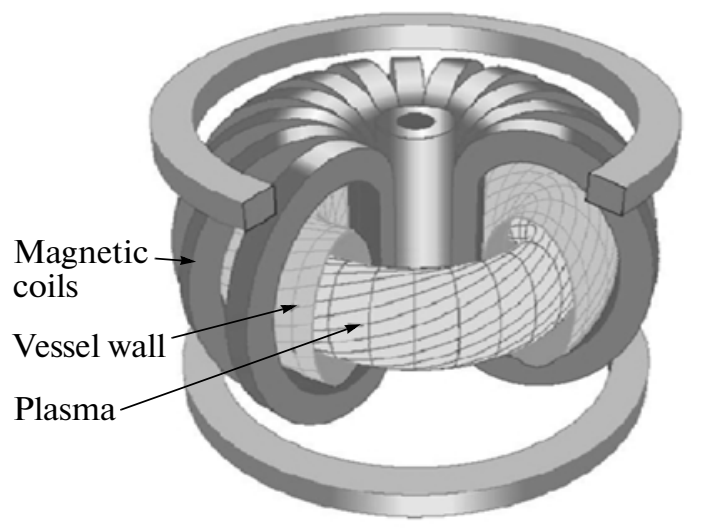

Fig. 1. Tokamak.

\footnotetext{
${ }^{1}$ The article is published in the original.
} 


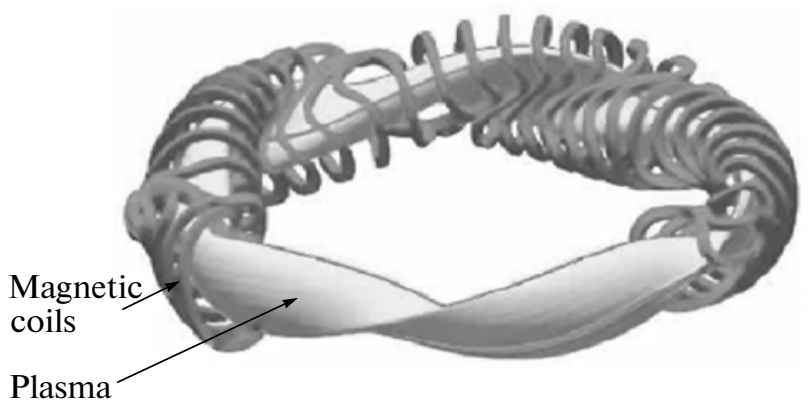

Fig. 2. Stellarator: the magnetic coils produce the nested closed magnetic surfaces; the vessel wall between plasma and magnetic coils is not shown.

from the vessel walls, tokamaks have the problem of plasma confinement instabilities and plasma disruptions in times of |is to ms. During the disruption the hot plasma and the major part of the magnetic energy of the plasma are deposited onto the vessel walls resulting in intense pulses of particle fluxes and high power deposition densities and the plasma is extinguished [33-35]. During normal operation of tokamaks, it has also been found that the loads to the vessel walls may oscillate, due to instabilities in the central plasma, such as "saw teeth" and "fishbone" oscillations [36] or instabilities in the boundary plasma, such as MARFES (multifaceted asymmetric radiation from the plasma edge) [37, 38], and different ELMs (edge localized modes), giving a very large power deposition [39].

In an advanced stellarator the closed nested magnetic surfaces for plasma confinement are produced only by specially shaped external magnets, generally supra conducting coils [40, 41] and thus the plasma life time is, in principle, not limited by decay of plasma currents which causes a loss of magnetic confinement.

A plasma current is not needed for the magnetic confinement and the lifetime of the plasma can in principle be very long. It depends on the power supplies for plasma heating, where the same techniques are used as for additional heating in tokamaks, and on the possibilities for sufficiently cooling of the highly loaded vessel wall areas.

In stellarators also oscillations of the energy content in the plasma and the wall loads with times in the range of seconds have been found and have been named "breathing" [42-45]. They originate from the influx of higher $Z$ atoms, such as metal atoms, which are released, mostly by sputtering at the vessel walls and result in radiation cooling of the plasma. In contrast to tokamaks, in stellarators the radiation cooling does not trigger a plasma disruption, the plasma near the vessel walls just cools down, thus power deposition at the vessel walls and sputtering gets reduced. The introduction of impurities gets lower and at continuous heating the plasma can heat up again. Breathing could be suppressed by using carbon plates at the divertors, because of the lower power loss by radiation of carbon atoms in the plasma.

\section{PLASMA CONFINEMENT}

Generally the magnetic plasma confinement must be sufficient but also limited. For fusion plasma at plasma density $n$ the energy confinement, given by an energy confinement time $\tau_{E}$, and the particle confinement, given by a particle confinement time $\tau_{\mathrm{p}}$ must fulfill the conditions:

$$
\begin{gathered}
-n \tau_{E} \geq 4 \times 10^{14}\left(\mathrm{~cm}^{-3} \mathrm{~s}\right)(\text { Lawson criterion }[46,47] \text { and } \\
-n \tau_{\mathrm{p} ; \mathrm{He}} \leq 2 \times 10^{15}\left(\mathrm{~cm}^{-3} \mathrm{~s}\right)
\end{gathered}
$$$$
\text { (ash removal criterion [48-53], }
$$

$$
\text { i.e: } \tau_{\mathrm{p}} / \tau_{E} \cong 3 \text { to } 5 \text {. }
$$

The first condition means that the energy produced in ignited fusion plasmas and deposited in the plasma by the $3.5 \mathrm{MeV}^{4} \mathrm{He}$ particles has to be confined long enough to keep the plasma hot, however, the equal sign means that for steady state operation this energy has to leave the plasma at the rate it is introduced.

The second condition means that the ${ }^{4} \mathrm{He}$ atoms, i.e. the ash, deposited in the plasma has to leave the plasma at the rate it is produced and introduced $[46,51,52]$. Actually, some of the ions and energetic $\mathrm{He}$ and D/T neutrals escaping from the plasma and impinging onto the vessel walls will be backscattered (i.e. recycled into the plasma) the others will be implanted and lost from the plasma. In order to keep the plasma density constant the $\mathrm{D} / \mathrm{T}$ atoms which are not recycled at the vessel walls have to be refuelled into the plasma. Recycling and trapping of the $\mathrm{He}$ ions is not of advantage, they have to be removed in the diverter. The numbers on the right hand side of the equations are proportional to the nuclear fusion power. In today's fusion experiments the energy confinement times are generally still too short, compared to what is needed for a fusion reactor, while the particle confinement times are mostly sufficient. Because the ${ }^{4} \mathrm{He}$ ash cannot be removed separately it will leave the plasma together with $\mathrm{D}$ - and $\mathrm{T}$-ions, i.e. $\tau_{\mathrm{p}, \mathrm{He}} \cong$ $\tau_{\mathrm{p}, \mathrm{D}} \cong \tau_{\mathrm{p}, \mathrm{T}}=\tau_{\mathrm{p}}$.

\section{LOADS TO THE VESSEL WALLS, PLASMA WALL INTERACTIONS}

The energy and the plasma particles which have to leave the plasma will impinge onto the vessel walls together with the neutrons, and this is the basic cause for the unavoidable plasma-solid interactions. These interactions at the vessel walls represent the transition between the hot plasma and the cold vessel walls. They are the most critical problems, both for the plasma, i.e. the control of the plasma density and composition, and especially for the plasma facing materials.

When the hot plasma, i.e. the particles and the energy impinge onto a solid wall there will be no local 

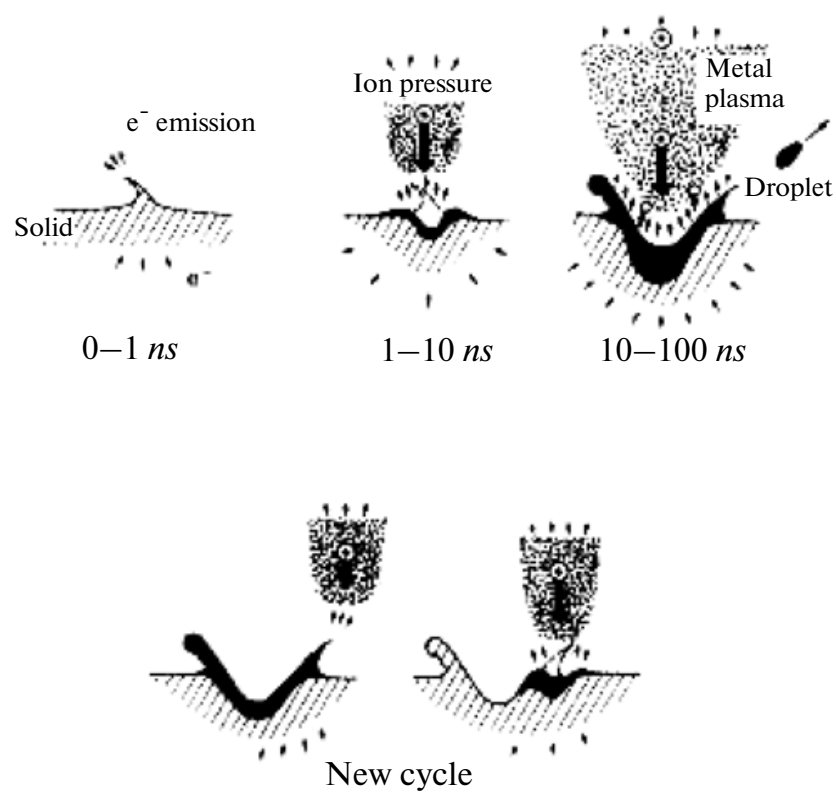

Fig. 3. Schematic of the ignition, movement and burn at the cathode of an electrical arc and the erosion by evaporation and droplet emission [62].

thermal equilibrium. Because of the extreme temperature and density step, the plasma wall interactions can only be understood on the basis of the different atomic processes which take place between the plasma and the materials surface [53]. The major processes at the plasma solid transition are: the electric coupling, the power deposition and the particle and neutron bombardment.

\subsection{The Electric Coupling between Plasma and Solid, Langmuir Sheath Potential, Arcing}

The electric coupling between the plasma and the solid means the built up of an electric field (Langmuir sheath potential [54]) and a magnetic pre-sheath [55] between the plasma and the vessel wall. The electric field is caused by the higher velocity of the electrons because of their lower mass, so that more electrons hit the surface than ions. The plasma charges up positively and the vessel walls negative, with a voltage of about $3 k T_{e}$, with $T_{e}$ being the electron temperature of the plasma near the vessel wall. This electric field causes a deceleration for the electrons and reflection for low energy electrons, acceleration for the ions, and a reduction of the power deposition. However, it may also cause the ignition and burn of electrical arcs between the solid, acting as the cathode and the plasma representing the anode. Traces of the cathode spots of these electrical arcs are seen at several vessel wall areas [56-63]. On the vessel wall, which acts as the cathode, material is eroded by the electrical arcs due to evaporation and emission of droplets (Fig. 3).

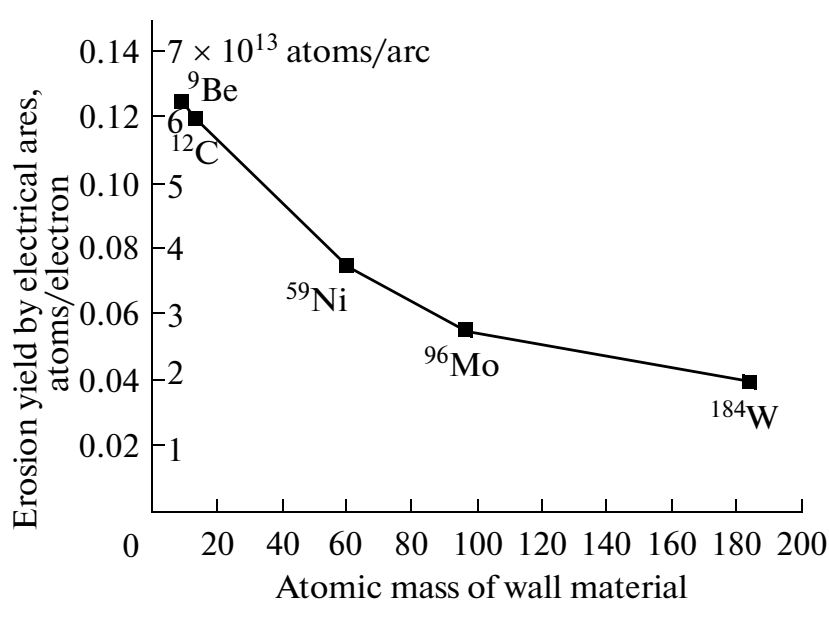

Fig. 4. Erosion yields by electric arcs (in atoms/electron, i.e. charge) and the estimated total number of atoms removed for an arc current of 5 to $10 \mathrm{~A}$ and a burn time of about 10 to $100 \mathrm{~ms}[62,67]$

In the magnetic field, for plasma confinement, the electrical arc moves in the retro-gate direction, i.e. against the direction of the Lorentz force $\mathbf{j} \times \mathbf{B}$ [64]. The total erosion yields depend on the length of the arc track and have been measured at several places, as summarized in Fig. 4 [65]. The erosion of the high $Z$ material $\mathrm{W}$ is about a factor 3 lower that the erosion of the lower $Z$ materials Be and $\mathrm{C}$. In fusion experiments the total erosion by electrical arcs at the divertor plates was found to be comparable with the erosion by sputtering [66]. In order to reduce the erosion, it is necessary to try to avoid the ignition of arcs. Arcs mostly ignite on pointed tips on the surface which give a high field emission current of electrons (Fig. 3) and at surface areas having a thin insulating oxide or carbide layer, which may polarize the Langmuir sheath potential, resulting in a larger electron emission. Cleaning of the surfaces by discharge reduces the ignition of electric arcs. Arcing may also be reduced by operating the boundary plasma at a low temperature and very stable. Arcing has the additional problem of the emission of small droplets of metals and dust pieces of carbon. These are found to be deposited on the vessel walls of several tokamaks [62, 67, 68]. The vessel wall, especially the divertor plates get very rough, which will increase the erosion by sputtering.

\subsection{The Power Deposition}

The power and the particle loads to the different areas of the vessel walls have been investigated at several of today's running plasma experiments with magnetic plasma confinement. Generally during normal operation about 50 to $70 \%$ of the power is emitted to the vessel walls by electromagnetic radiation and about $30 \%$ is diffusing into the boundary plasma. Here a parallel power flux in the $100 \mathrm{MW} / \mathrm{m}^{2}$ is expected. 


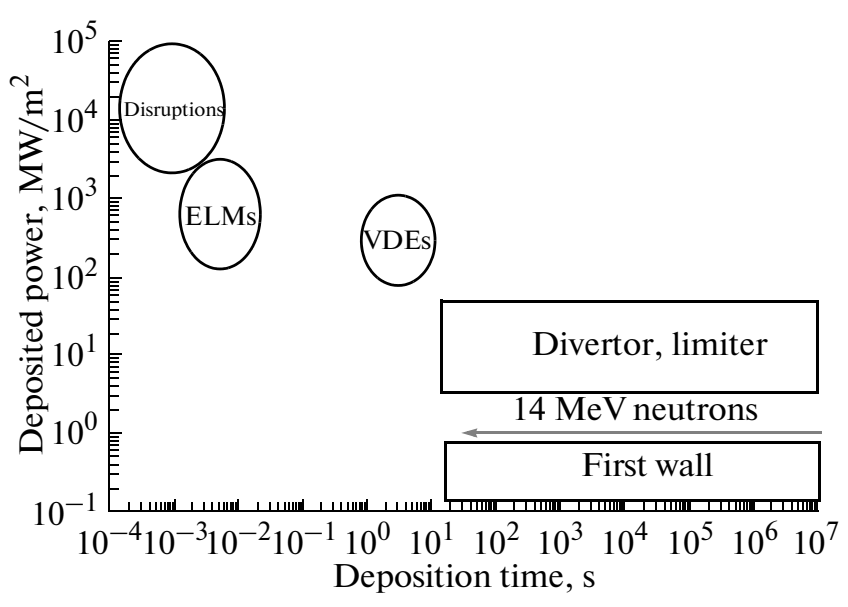

Fig. 5. Expected power loads to the different areas of the vessel walls in fusion devices such as ITER [70].

The energy leaving the plasma is deposited mostly onto the divertor plates and limiters, but a fraction is also deposited onto all vessel wall areas by electromagnetic radiation and energetic neutrals. In today's fusion experiments the plasma lifetime and thus the power and plasma particle deposition onto the vessel walls is for times in the 5 to few 10 seconds range while in a future fusion reactor quasi steady state operation in the few $1000 \mathrm{~s}$ range or continuous operation are envisioned. In addition, for a magnetically confined plasma a fraction of the plasma energy and particles are lost during plasma instabilities and are deposited predominantly onto special components of the vessel walls, especially onto protection limiters and divertor plates, in times of the order of is to ms. The power may be deposited in pulses of hot plasma, i.e. energetic electrons, ions and neutrals. The power deposition at the vessel walls causes heating which may finally lead to local melting, emission of micro-particles and droplets and large sublimation, including "blooming" at carbon surfaces, such as at divertor plates and protection limiters and finally cracking at surface layers [69].The expected power loads for a first ignited fusion plasma [70] are summarized in Fig. 5.

3.2.1. Power removal, tolerable power deposition onto different materials. For an extended uniform deposition of a power density $\dot{q}$ onto a wall tile being cooled at the rear side to a temperature $T_{0}$ and reaching a temperature $T_{s}$ on the heated front side, the power density $\dot{q}$, which is removed by thermal conduction in one dimension through wall tiles having a thermal conductivity $K(T)$ and a thickness $d$, is given by [71-73]

$$
\begin{gathered}
\dot{q}=\frac{1}{d} \int_{T_{0}}^{T_{s}} K\left(T^{\prime}\right) d T^{\prime}, \\
\text { or } \dot{q} \cong(1 / d)\left(T_{s}-T_{0}\right)\langle K(T)\rangle .
\end{gathered}
$$

The temperature dependence of the thermal conductivity is generally given by [72]

$$
K(T)=1 /(a T+b) \text {. }
$$

The constants $a$ and $b$ can be determined by fitting to measured values, see Fig. 6 .

The thermal conductivity of the relevant materials has been measured at several places and published in review articles [74].

Inserting Eq. (2) in Eq. (1) and integration gives for the removable power:

$$
\dot{q}=\frac{1}{a d} \ln \frac{a T_{s}+b}{a T_{0}+b} .
$$

The calculated power which is removed by thermal conduction through $0.01 \mathrm{~m}$ thick well annealed materials, i.e. without damage, according to (1) or (1a) or (3) and a rear temperature of about $T_{0} \cong 500 \mathrm{~K}$ and the maximum temperature at the heated side is plotted for different materials in Fig. 7.

At neutron irradiation the thermal conductivity of $C$ drops by up to a factor of 2 , and for Be by about $30 \%$, and the removable power is reduced by these factors. This may likely be also the case for the doped graphite, where the carbon is mostly graphitised [75]. For hydrogen or He implantation into materials including $\mathrm{W}$ the trapped gas atoms reduce the thermal conductivity and the removable power is also reduced [76].

For $0.01 \mathrm{~m}$ thick wall tiles about $35 \mathrm{MW} / \mathrm{m}^{2}$ is the largest power density which can be continuously removed by thermal conduction is with $\mathrm{Cu}$. With well annealed $\mathrm{W}$ about from 12 to $20 \mathrm{MW} / \mathrm{m}^{2}$ can be permanently removed while with carbon fibre enforced carbon, CFC, (not yet damaged by neutron irradiation) up to $22 \mathrm{MW} / \mathrm{m}^{2}$ can be continuously removed. With Mo up to about $20 \mathrm{MW} / \mathrm{m}^{2}$, with $\mathrm{Al}$ up to $12 \mathrm{MW} / \mathrm{m}^{2}$, with Be up to about $7 \mathrm{MW} / \mathrm{m}^{2}$, with doped graphite between 5 and $15 \mathrm{MW} / \mathrm{m}^{2}$ while for fine grain graphite (Poco and EK98) only up to $5 \mathrm{MW} / \mathrm{m}^{2}$ can be continuously removed. For $\mathrm{C}$ the maximum temperature is assumed to be limited by sublimation of about $1 \mathrm{~mm} / \mathrm{y}$. Generally, the final limit for power removal is surface melting and sublimation, but in the surface layers also very large stresses above tolerable yield stress may built up [73].

Equation (3) allows also to calculate the surface temperature $T_{s}=T(d)$ and the temperature distribution $T(\xi)$ in the wall tiles for deposition of a power density $\dot{q}$ at the surface and a temperature $T_{0}$ at the rear side, giving

$$
T(\xi)=\left(T_{0}+\frac{b}{a}\right) e^{\dot{a} a \xi}-\frac{b}{a} .
$$

The temperature increases exponentially toward he heated side. Some distributions calculated for different deposited powers for $\mathrm{W}, \mathrm{C}$ and Be are shown in Fig. 8.

The temperature at the cooled side will be about 100 to $800^{\circ} \mathrm{C}(400$ to $1100 \mathrm{~K})$, depending on the 

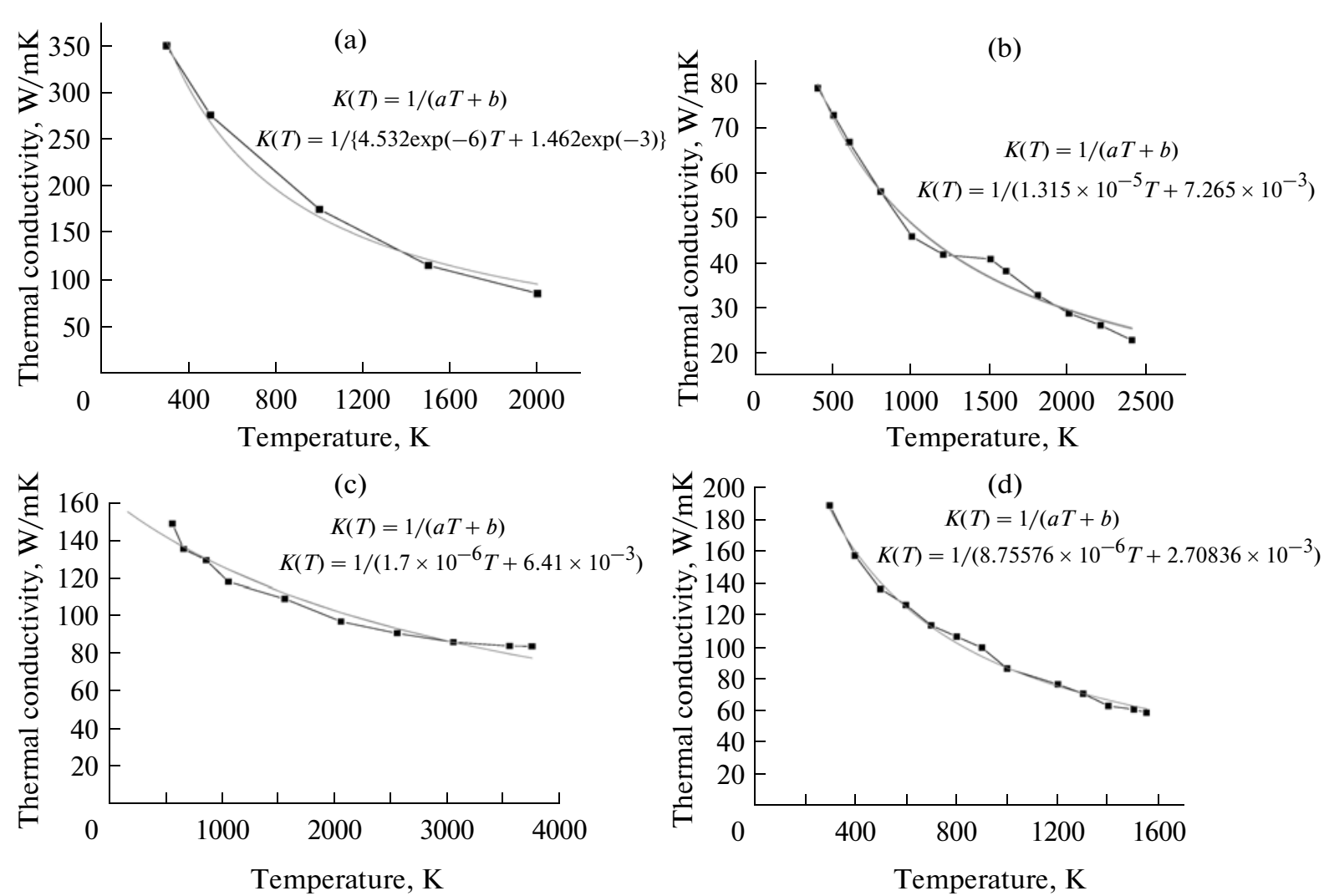

Fig. 6. Algebraic fit to the measured thermal conductivities of $\mathrm{W}, \mathrm{Be}$, and two types of carbon, without neutron damage: $\mathrm{CFC}$, CX2002U (a); C, poco, EK98 (b); W (c); Be (d).

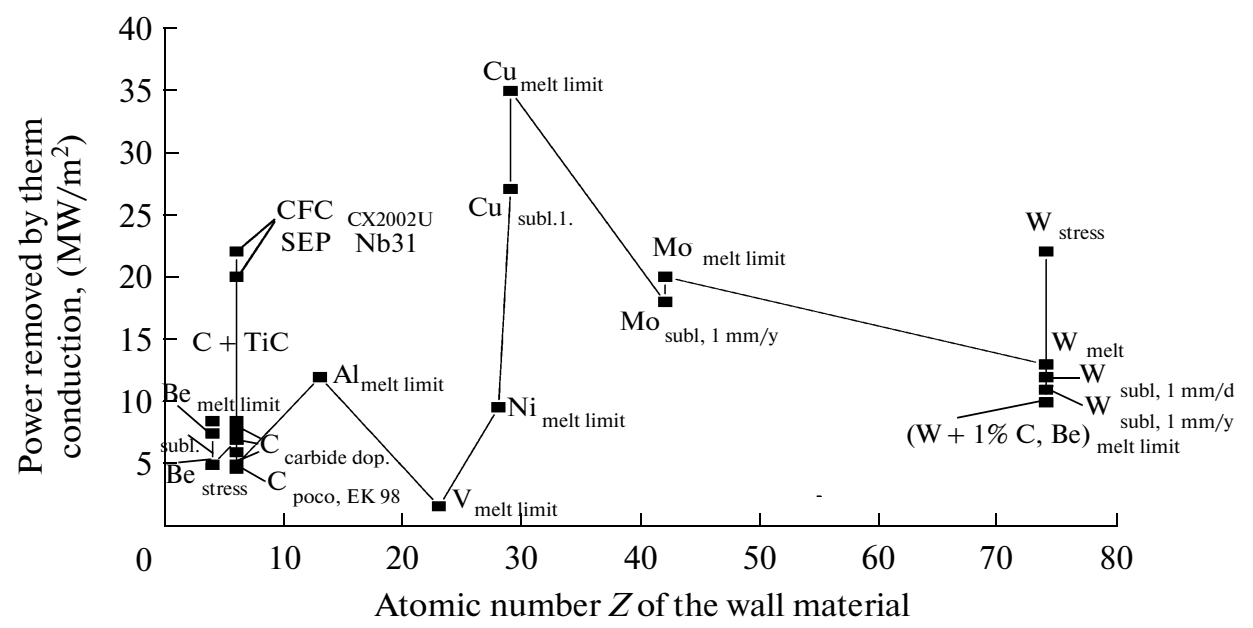

Fig. 7. The power which is removed by thermal conduction in one direction for a rear temperature of about $T_{0}=500 \mathrm{~K}$ and the maximum temperature at the heated side.

mounting, the power to be continuously removed and the cooling conditions. For $1 \mathrm{~cm}$ thick plates of $\mathrm{Be}, \mathrm{W}$, and CX2002U fibre enforced carbon, and fine grain graphite (Poco graphite, EK 98) deposited powers of 1 to $40 \mathrm{MW} / \mathrm{m}^{2}$ can be continuously removed.
For the large deposited powers the temperature gradients become very steep, i.e. for $\mathrm{W}$ up to about $1000 \mathrm{~K} / \mathrm{cm}$, causing a high stress gradient, with compression in the surface layers and tension deeper in the material. Gas atoms implanted into the hot com- 

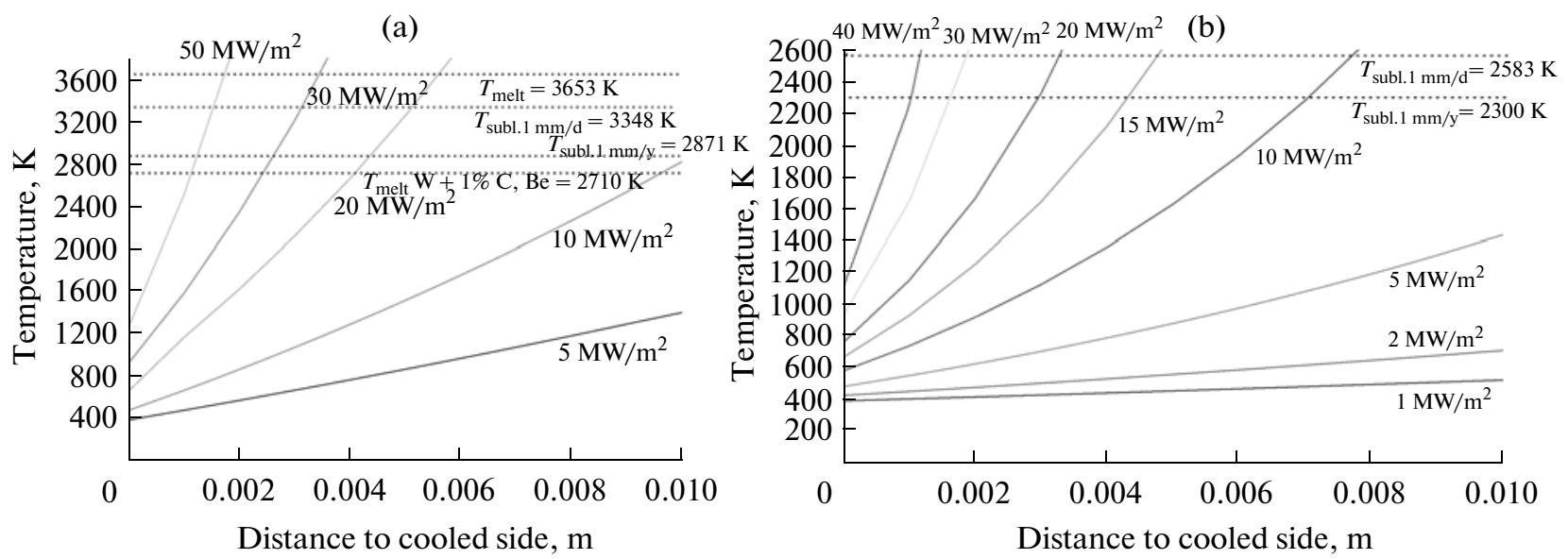

Fig. 8. Calculated temperature distribution for $\mathrm{W}$ and $\mathrm{C}$ at different power depositions at the surface and a temperature of about 100 to $800 \mathrm{~K}$ at the cooled side: W (a); C, poco, EK98 (b).

pressed surface layers may be pushed into deeper layers which are under tension, i.e. much deeper than the implantation range. This has indeed been found in experiments [76-78]. According to Fig. 7, it is again confirmed that for $0.01 \mathrm{~m}$ thick $\mathrm{W}$ and for Be the maximum power which is removed by thermal conduction is about $20 \mathrm{MW} / \mathrm{m}^{2}$ and 5-6 MW/ $/ \mathrm{m}^{2}$ respectively. For higher deposited powers the surface melts.

3.2.2. Deposition of power pulses, energy pulses, power removal. If the surface of a material at temperature $T_{0}(\mathrm{~K})$ receives a power density $\dot{q}\left(\mathrm{~W} / \mathrm{m}^{2}\right)$ for a short time $t$, the surface temperature $T(0 ; t)$ increase is approximately given by [79]

$$
T(x=0, t)=T_{0}+\dot{q} \sqrt{t} \frac{2}{\sqrt{\pi \rho\langle c(T)\rangle\langle K(T)\rangle}} .
$$

With $\rho\left[\mathrm{kg} / \mathrm{m}^{3}\right]$ being the density, $\langle c(T)\rangle[\mathrm{J} /(\mathrm{kg} \mathrm{K})]$ the average specific heat and $\langle K(T)\rangle[\mathrm{W} / \mathrm{mK}]$ the average thermal conductivity of the material. In deriving this Eq. (5) it was assumed that the specific heat and the thermal conductivity do not depend largely on the temperature of the material. This means that Eq. (1) holds only approximately and average values have to be used for $c(T)$ and $K(T)$ for the temperature range of interest. Further an infinitely thick target was assumed, i.e. a thickness $d$ of the target larger than the penetration depth, $d^{*}$, of the power into the material during the heating time $t$ [79], i.e. $d \geq d^{*}$ with

$$
d^{*}=3 \sqrt{t} \sqrt{\frac{\langle K(T)\rangle}{\rho\langle c(T)\rangle}},
$$

or a heating time shorter than a time $t^{*}$, which for a given thickness $d$ is given by

$$
t \leq t^{*}=\frac{d^{2}}{9} \frac{\rho\langle c(T)\rangle}{\langle K(T)\rangle}
$$

The penetration depths for $1 s$ power deposition as well as the times $t^{*}$ it takes for the power to penetrate $0.01 \mathrm{~m}$ thick wall tiles have been calculated for several wall materials and are shown in Figs. 9 and 10.

If the material is thinner than $d^{*}$, and the rear side is sufficiently cooled the formulae developed for continuous power deposition apply. The times for penetrating $0.01 \mathrm{~m}$ thick wall tiles is mostly of the order of up to 2 to $5 \mathrm{~s}$, except for fine grain graphite (POCO and EK98), where the thermal conductivity is relatively low. Again, for a power deposition longer than $t^{*}$ the formulae for continuous power removal apply.

The temperature gradient near the surface during heating can be also calculated. With the depth and time dependent detailed formula $T(x, t)$ [97], this gives:

$$
\frac{\partial T_{s}}{\partial x}=\frac{\dot{q}}{K}
$$

For a deposited power of 1 to $10 \mathrm{MW} / \mathrm{m}^{2}$ the temperature gradient near the surface is of the order of $10^{3}$ to $10^{4} \mathrm{~K} / \mathrm{m}$. The increase of the surface temperature with heating time is given approximately by Eq. (4).

The material erosion by short power pulses has been investigated by J. Linke et al. [70] with intense electron beams. For metals a surface layer melts and part of the molten layer is finally lost. For fine grain carbon small carbon particles and grains are emitted, as shown in the Figs. 11 and 12.

\subsection{The Particle Bombardment}

In fusion devices the plasma density and particle balance as well as the introduction of wall atoms into the hot plasma and the lifetime of the highly loaded wall tiles are determined by the particles which are lost from the plasma and impinge onto the vessel walls, by their backscattering at the wall material and by implantation, trapping and release as well as erosion 


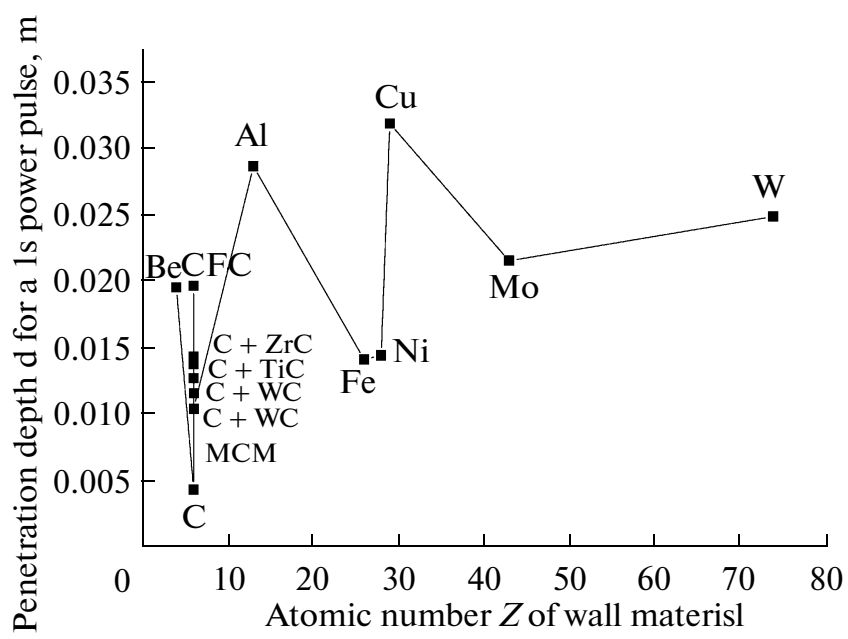

Fig. 9. The penetration depths for $1 s$ power deposition calculated for several wall materials.

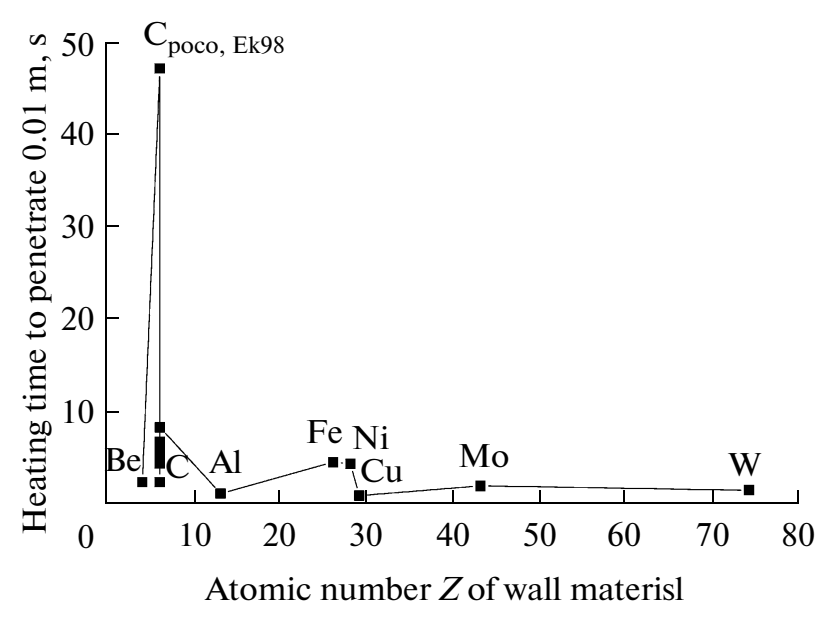

Fig. 10. Time $t^{*}$ of power deposition until the heat has reached the rear side at $d=0.01 \mathrm{~m}$ for different materials.
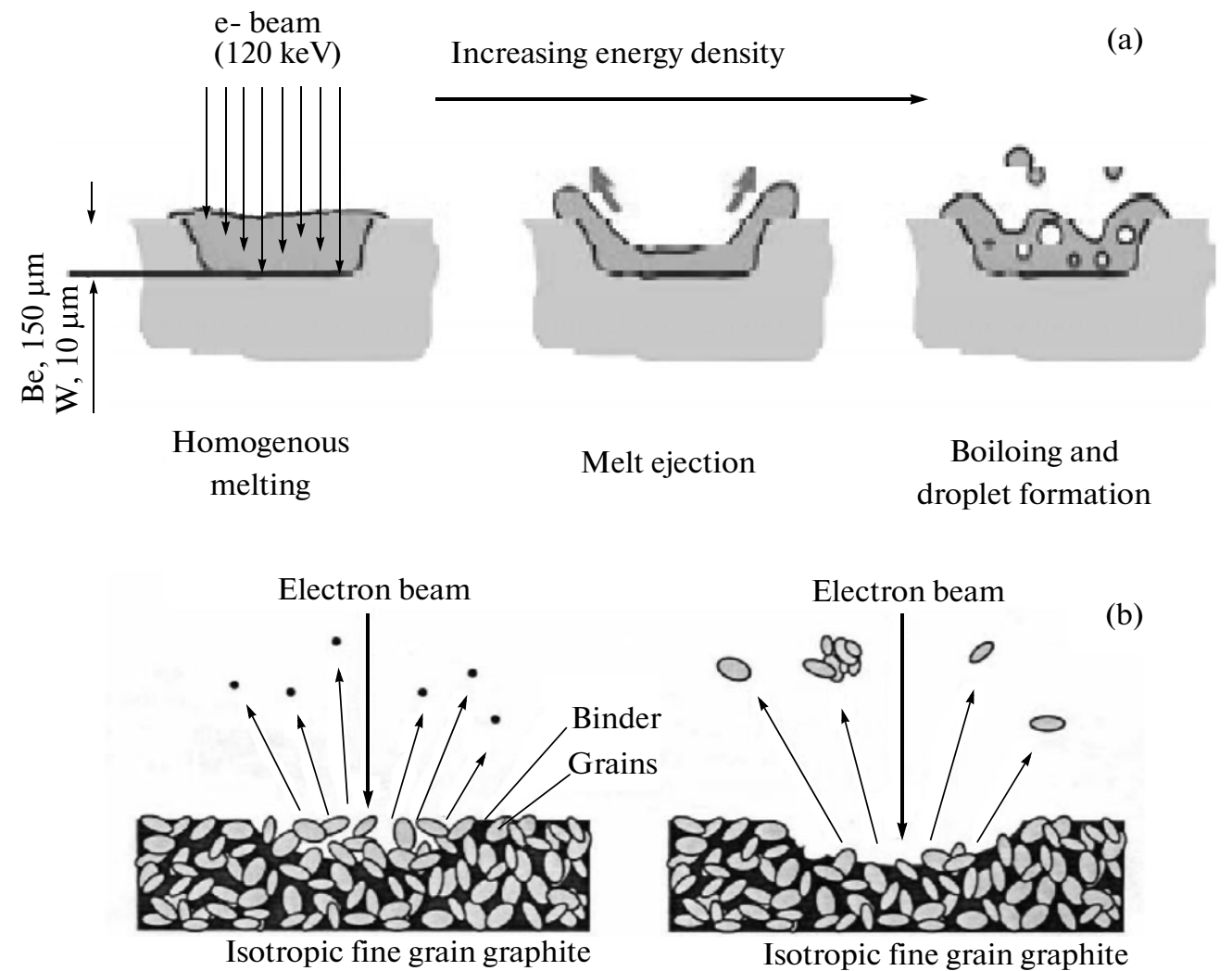

Fig. 11. Erosion character change of power deposition increase for metal (a) and at fine graphite (b).

by sputtering, arcing $[53,80]$ evaporation and destruction by power pulses [70].

The particle fluxes leaving the plasma, their distribution along the vessel walls and their energies for the planned fusion device ITER (International Tokamak Experimental Reactor), which will likely finally operate with an ignited $\mathrm{D} / \mathrm{T}$ plasma, have been calculated by
D. Reiter et al. with the computer code B2 EIRENE [81-83]. The geometry of the vessel wall is shown in Fig. 13, while the results for the fluxes are shown in Fig. 14.

The plasma ions and neutrals impinging onto the vessel walls are partly backscattered and partly implanted and may be trapped in the wall material. 
(a)

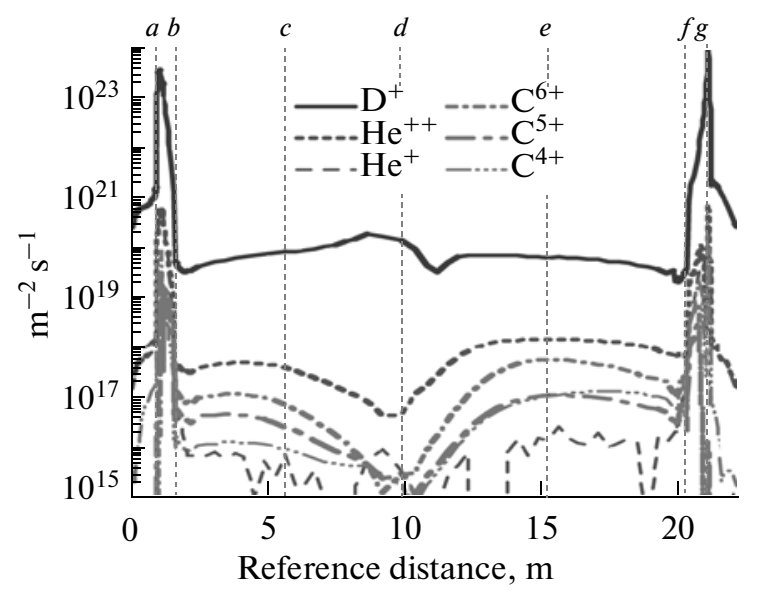

(b)

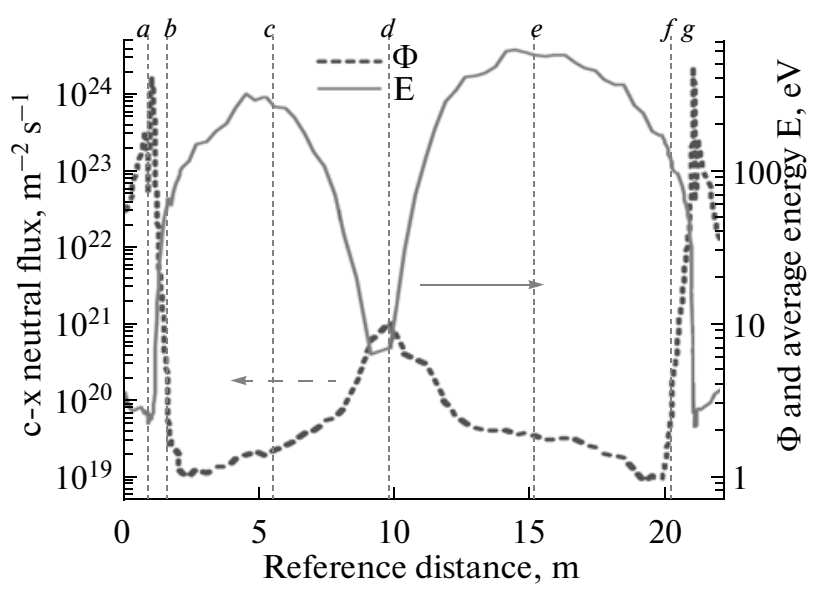

Fig. 14. Calculated ion and neutral fluxes to the vessel walls of ITER 585. The reference distance poloidal along vessel walls can be seen in Fig. 13.

The gas atoms may accumulate at depth where the compression stress changes into tensile stress, at much larger depth than the implantation range. This has been found for He implantation at the $\mathrm{W}$ divertor in the LHD stellararor [87, 88].

3.3.2. Erosion at the vessel. Several processes contribute to erosion at the vessel walls, such as evaporation, arcing and sputtering [89-94]. They cause a thinning of the vessel walls. The eroded wall atoms may partly enter the central plasma where they represent impurities which increase the electrical resistance and cool the plasma by radiation. Finally they will be re-deposited onto other wall areas [67]. The erosion will also limit the lifetime of the wall tiles at the higher loaded wall areas, such as the divertors. In order to reduce the erosion of the vessel walls and to reduce the peak power at the divertor plates and limiters it is tried to operate the boundary plasma at a low temperature.

Sputtering has been widely investigated with ion beams [89-94], some yields for relevant single atom (a)

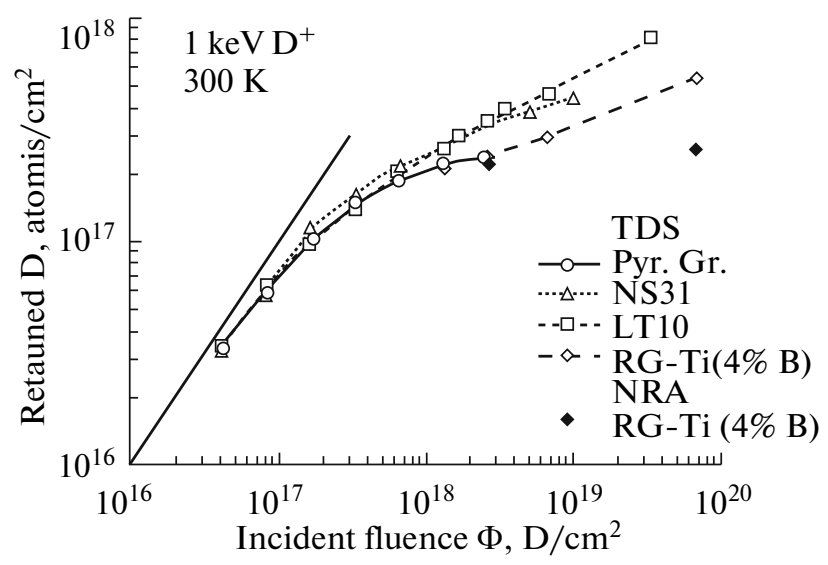

(b)

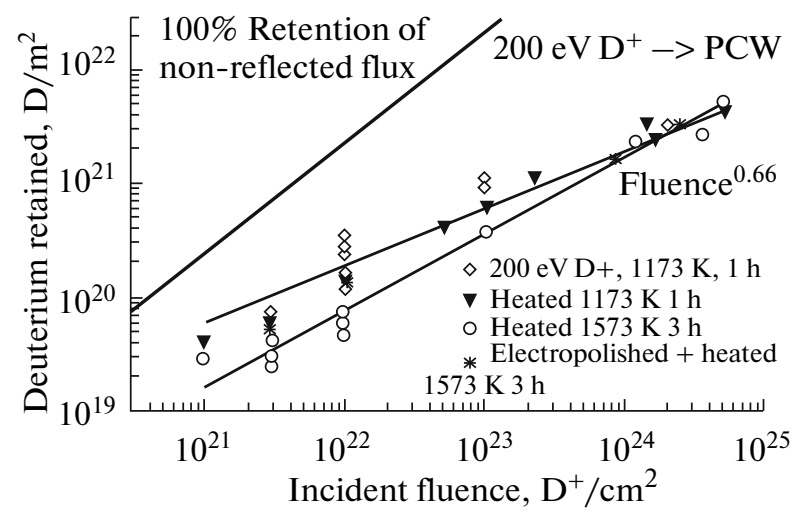

Fig. 15. Trapping of $200 \mathrm{eV} \mathrm{D}^{+}$implanted to high fluences into graphites (a) and previously annealed polycrystalline W (PCW) (b) at $R T$ as measured by thermal desorption spectroscopy (TDS) and nuclear reaction analysis (NRA).

materials are shown in Fig. 16. With these data the erosion by sputtering at the vessel walls of ITER for the wall fluxes of Fig. 14 have been calculated [82], the results are shown in Fig. 17. If erosion by arcing is included the erosion may be up to a factor 2 higher. Fig. 18 shows calculated erosion rates of several single atom solids per second for the wall fluxes of ITER. The largest erosion will take place for all materials at the reference distances around 8 and 11 at the divertor. For $\mathrm{C}$ the erosion is very large due to the chemical erosion of $\mathrm{C}$ at hydrogen bombardment [95]. The lowest erosion is found for W. For all materials this turns out to be of the order of one $\mathrm{kg} / \mathrm{cm}^{2}$ in one FPY. The erosion will also limit the lifetime of the wall tiles at the higher loaded wall areas. The time to erode $5 \mathrm{~mm}$ was calculated and is shown in Fig. 19.

In order to reduce physical sputtering at the vessel walls, and to reduce the peak power at the divertor plates and limiters intersected by the LCFS (Last Closed magnetic Flux Surface), it is tried to operate the boundary plasma at sufficiently low temperatures (high recycling divertor). A first $\mathrm{D} / \mathrm{T}$ fusion plasma is 


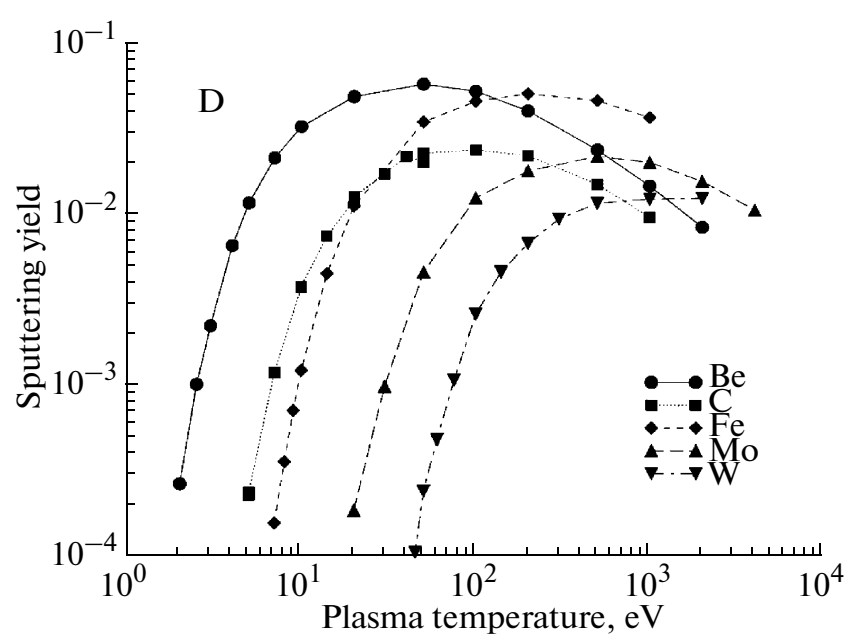

Fig. 16. Sputtering yield for several elemental materials as computed for deuterium plasma.

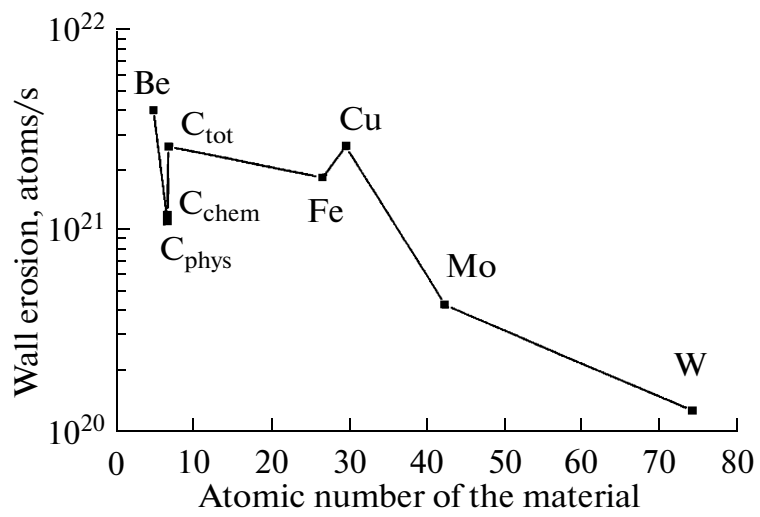

Fig. 18. Erosion by sputtering for several materials at the area of largest erosion.

planned to burn with a nuclear power of $0.5 \mathrm{GW}$ for a time of $>400$ up to 3000 seconds in the ITER. A schematic cut in a poloidal plane through the toroidal vessel walls is shown in Fig. 13. The distribution of the loads to the different areas of the vessel walls depends on the structure of the magnetic field and the geometry of the vessel walls. Ions and electrons move nearly freely along the magnetic field lines, while they only slowly diffuse and drift perpendicular to the magnetic surfaces. Magnetic field lines outside the LCFS intersect at the vessel walls with a limiter or in a partly separate volume at divertor tiles. A divertor is also planned for ITER, see Fig. 13 (here the divertor plates are identified by $a, b, f, g)$. At these areas the most intensive plasma solid interactions and large power and particle loads are observed, with maxima at areas where magnetic surfaces just outside the LCFS intersect. All other first wall areas at larger distances from the LCFS

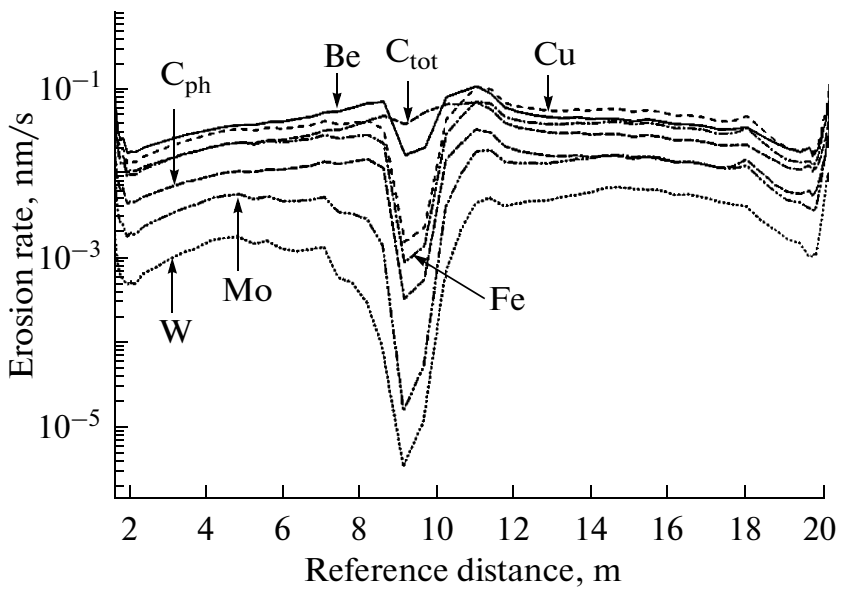

Fig. 17. Calculated erosion rates of several single atom solids per second for the wall fluxes of ITER (reference distance corresponds to Fig. 14).

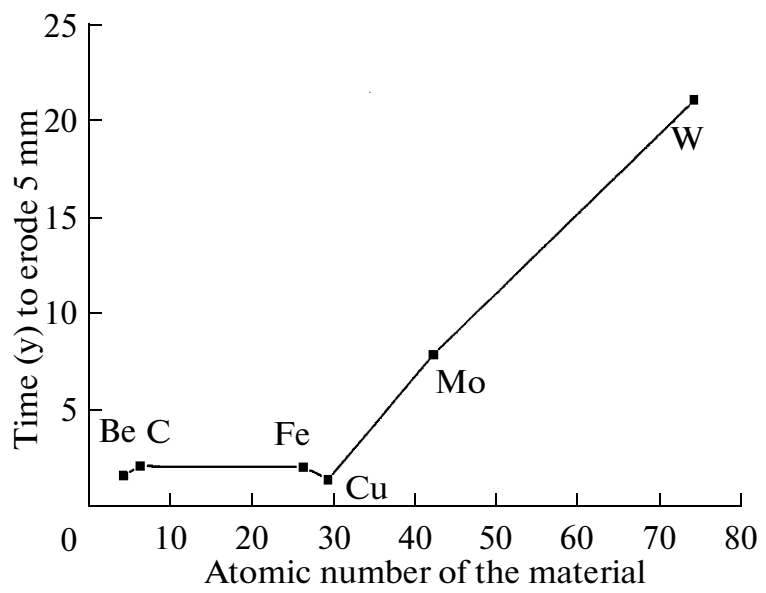

Fig. 19. The time to erode $5 \mathrm{~mm}$ of plasma faced materials made from different materials.

receive only smaller plasma, i.e. smaller particle and power fluxes. Besides ions and electrons a major particle load especially at the more remote first wall are energetic neutral hydrogen atoms. They are mostly produced by charge exchange processes between neutral hydrogen atoms entering the plasma and ions in the plasma boundary and by recombination in the plasma. The energetic neutrals may also originate from "shine through" of intense neutral beams, which are injected for plasma heating. Further, power is deposited on all vessel walls by electromagnetic radiation. At the more remote first wall vessel areas the particle and power flux densities are lower than at the limiters and diver-tor plates; however, due to the first wall representing a much larger area, their total contribution to the plasma wall interaction phenomena, such as sputtering, is comparable or even larger than the interactions at divertors and limiters. 


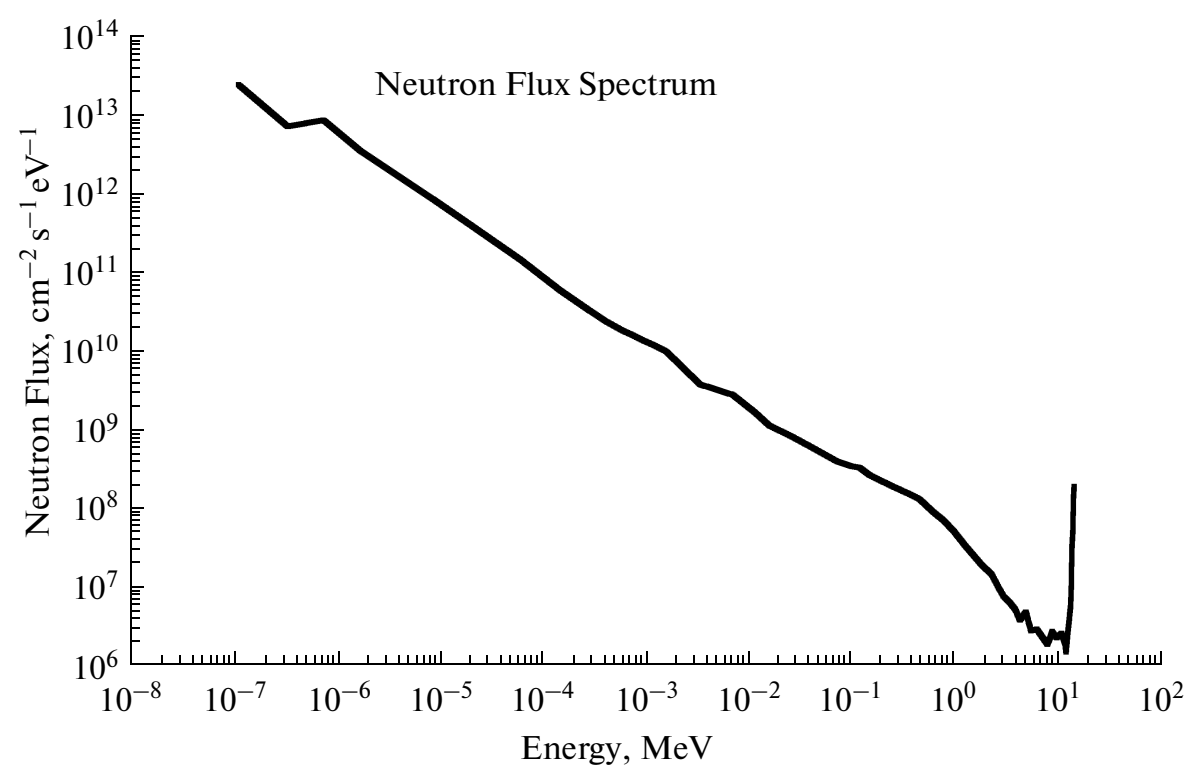

Fig. 20. Calculated spectrum for the neutron bombardment on the first wall of ITER.

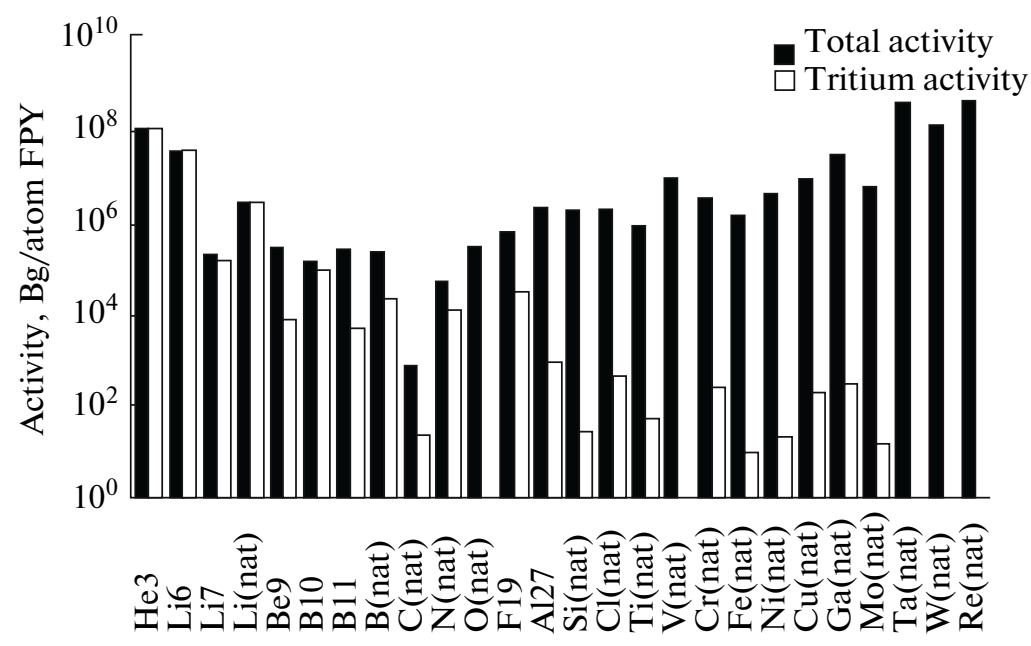

Element

Fig. 21. Induced activity for different elements and isotopes.

3.3.3. Neutron bombardment of the vessel walls. For an ignited D/T plasma, such as ITER, a total primary flux of about $10^{20}, 14.1 \mathrm{MeV} \mathrm{n} / \mathrm{m}^{2}$ is expected. Due to scattering and nuclear reactions in the vessel wall material and the blanket surrounding the vessel wall the total neutron flux is expected to be about a factor 100 higher, a distribution calculated for ITER is shown in Fig. 20 [96].

Induced activity for different elements and isotopes are shown in Fig. 21. The neutron flux causes transmutations and radiation damage in the wall material, resulting in modification of the thermo-physical properties. For the lower $Z$ materials a considerable amount of $T$ is produced. Actually the ${ }^{10} \mathrm{~B}$ is trans- muted to a large extend to $\mathrm{He}$ and $\mathrm{T}$ (Fig. 22). This means that only ${ }^{11} \mathrm{~B}$ can be used at the vessel walls. For the same reason Be cannot be used at the plasma-facing vessel walls of a longer burning $\mathrm{D} / \mathrm{T}$ plasma.

For a fusion reactor for all plasma facing wall areas materials have to be found and tested which can stand the power, the particles and the neutron loads from the plasma and where the interaction processes with the plasma, result in the smallest plasma degradation, or rather in an improvement of the plasma performance. The importance of using appropriate materials at the plasma facing areas of the vessel walls has been demonstrated in today's plasma experiments by vessel wall cleaning and coating of the vessel walls with $\mathrm{C}$ (car- 
(a)

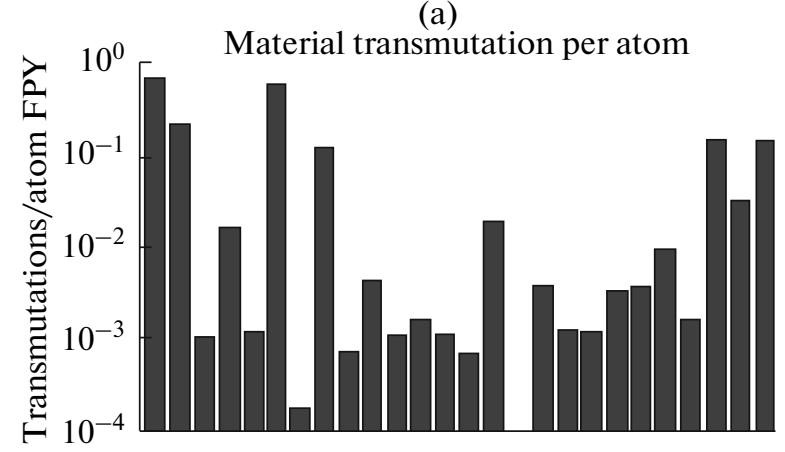

(b)

Hydrogen production per atom

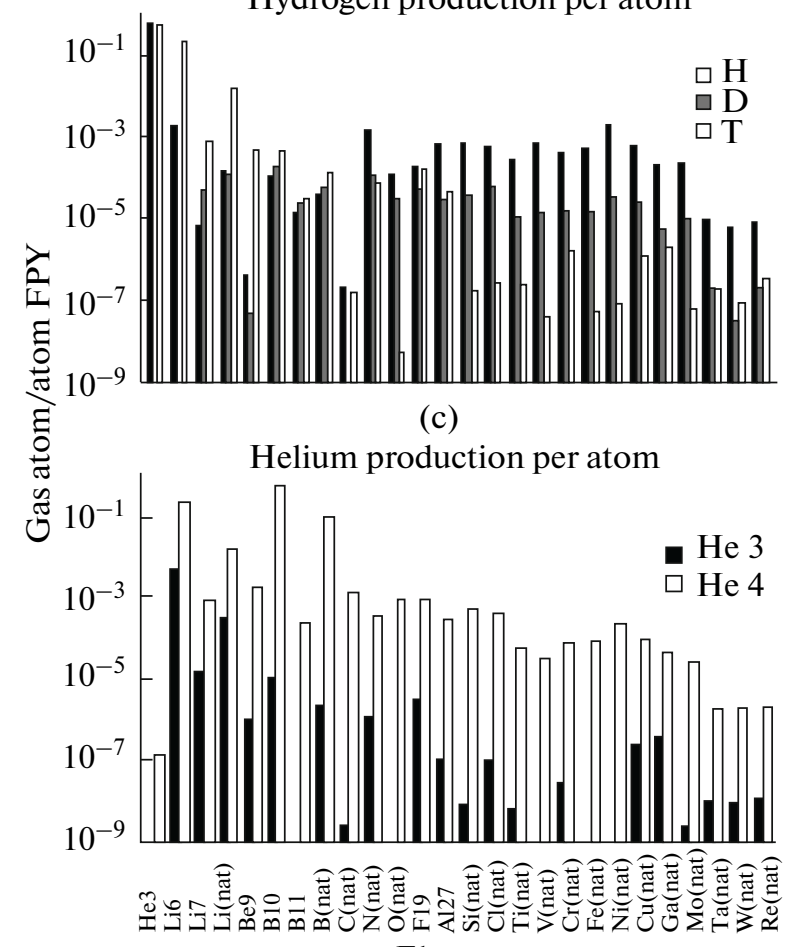

Element

Fig. 22. Calculated transmutations (a), hydrogen isotope (b) and $\mathrm{He}$ isotope (c) production for several materials after one Full Power Year (FPY) operation for the neutron flux of Fig. 21 calculated for ITER [96].

bonization), $\mathrm{Be}, \mathrm{Si}$ (siliconisation) or $\mathrm{B}_{4} \mathrm{C}$ (boronisation) [97], which also getter $\mathrm{O}$ very well or materials with low erosion and low hydrogen isotope trapping such as W and Mo.

\section{SUMMARY, CONCLUSION}

For an ignited D/T fusion plasma which is confined by nested closed magnetic surfaces the necessary power, particle and neutron loads to the surrounding vessel walls, especially to limiters and divertor plates, where magnetic field lines directly intersect, are very high, i.e:
- a power of several MW/ $\mathrm{m}^{2}$, which may be deposited in pulses or continuously;

-a flux of D, T and He atoms with energies in the $100 \mathrm{eV}$ to $\mathrm{MeV}$ range, of order of $10^{23} / \mathrm{s} \mathrm{m}^{-2}$;

-a flux of 14.1 MeV neutrons having for ITER a predicted total power of about $400 \mathrm{MW}$.

At the highly loaded areas the $\mathrm{W}, \mathrm{C}$ and Be which are used in today's fusion experiments, may stand the loads from an ignited D/T fusion plasma only for relatively short discharge times, such as in today's tokamaks. For longer discharge times the materials properties are largely modified by the high power deposition with simultaneous gas implantation and trapping in the damage sites produced by the neutron bombardment. In addition, the plasma-facing surface layers are continuously modified by the erosion at the erosion dominated wall areas and re-deposition of the eroded atoms also onto other deposition dominated vessel wall areas. After some discharge time all materials ever mounted at some vessel wall area are found on all vessel wall areas, resulting in a modified mixed wall material $[67,98]$. The properties of these mixes materials are mostly different to the properties of the materials initially installed [99].

For building in the future a longer operating fusion devices and a $\mathrm{D} / \mathrm{T}$ fusion reactor an extended material program and/or a redesign of divertor geometries may be necessary, such as a "Li divertor" on the basis of capillaries of $\mathrm{V} \mathrm{W}$ or $\mathrm{C}$, through which liquid $\mathrm{Li}$ is pressed from behind [100-102], in order to form continuously a $\mathrm{Li}$ film on the plasma-exposed surface. The ideas of liquids at the first wall have been already discussed theoretically [103] and have been investigated in some tokamaks, such as the T-11M tokamak (TRINITI, RF), the FTU (Italy) and the CDX-U (USA). The main feature of CDX-U toroidal limiter was a free liquid Li surface.

For the vessel wall areas, which are not hit directly by magnetic field lines and thus receive lower loads from the plasma, Be, carbon, doped carbon, and even stainless steel or Inconel have been and may be used for future machines. However for fusion reactors operating for longer times additional problems may come into play. These are the formation of the "mixed material" with different compositions and still mostly unknown properties. Further, the transmutations, dislocation damage and radioactive activation of all wall materials due to neutron bombardment will become very critical.

It is a great pleasure to thank the colleagues from the Surface Physics and the Materials Physics Divisions at IPP for many kind comments and support in summarising these very complex materials problems, Hans-Peter Zehrfeld often helped in getting the computer operating, as necessary. 


\section{REFERENCES}

1. R. Aymar, V. Chuyanov, and M. Huget, in Proc. $16^{\text {th }}$ IAEA Fusion Energy Conf., Montreal, Canada, 1997 (IAEA, Vienna, 1998).

2. R. Aymar et al., J. Nucl. Mater. 307-311, 1 (2002).

3. G. Federici et al., J. Nucl. Mater. 290-293, 260 (2001).

4. G. M. McCracken and P. Stott, Fusion, the Energy Source of the Universe. Complimentary Science Series (Elsevier, Amsterdam, 2005).

5. D. J. Rose and M. Clark, Jr., Plasmas and Controlled Fusion (MIT, Cambridge, MA, 1961).

6. U. Schumacher, Fusions Forschung. Eine Einfuhrung (Wissenschaftliche Buchgesellschaft, Darmstadt, 1993).

7. F. Engelmann, Physics of Plasma-Wall Interactions in Controlled Fusion, NATO ASI Ser. B: Physics, Vol. 113, p. 15 (Plenum, New York, London, 1984).

8. L. A. Artsimovich, in Plasmaphysics and Contr. Nucl. Fusion Research, Proc. of the 3rd Intern. Conf., Novosibirsk, 1968 (IAEA, Vienna, 1969), p. 175.

9. L. A. Artsimovich, Nucl. Fusion 12, 215 (1972).

10. H. P. Furth, Nucl. Fusion 15, 487 (1975).

11. L. A. Artsimovich, Controlled Thermonuclear Reactions (Oliver and Boyd, London, Edinburg, 1994).

12. J. A. Wesson, Tokamaks, Oxford Eng. Sci. Ser. 48 (Calderon, Oxford, 1997).

13. L. Spitzer, Phys. Fluids 1, 245 (1958).

14. L. Spitzer, Sci. Am. 109, 28 (1958).

15. L. Spitzer, Plasma Physics and Thermonuclear Research, Progress in Nuclear Energy, Ser. XI (Pergamon, London, New York, Paris, Los Angeles, 1959), p. 107.

16. G. Grieger, H. Renner, and H. Wobig, Nucl. Fusion 25, 1231 (1985).

17. G. Grieger et al., Phys. Fluids B 4, 2081 (1992).

18. B. A. Carreras, G. Grieger, and J. H. Harries, Nucl. Fusion 28, 1613 (1988).

19. F. Herrnegger, F. Rau, and H. Wobig, Max Plank Inst. Rep. IPP 2/343 (Garching, 1999).

20. A. A. Galeev and R. Z. Sagdeev, Nucl. Fusion, Suppl., 45 (1972).

21. V. S. Chan, C. M. Greenfield, and L. L. Lao, Nucl. Fusion 40, 1137 (2000).

22. R. H. Bickerton, J. W. Connor, and J. B. Taylor, Nature 229, 110 (1972).

23. M. Murakami, H. E. St. John, T. A. Carsper, et al., Nucl. Fusion 40, 1257 (2000).

24. M. Murakami, J. D. Callen, and L. A. Berry, Nucl. Fusion 16, 437 (1976).

25. N. Ohyabu, Nucl. Fusion 9, 1491 (1979).

26. E. Tsitrone, J. Nucl. Mater. 363-365, 12 (2007).

27. Proc. of IAEA Techn. Committee Meeting on Inductive Current Drive in Tokamaks, Report CLM-CD (Culham Labor., 2003).

28. St.-Laurent, Nucl. Fusion 40, 1245 (2000).

29. T. Oikawa, Nucl. Fusion 40, 1245 (2000).

30. O. Gruber, R. Wolf, et al., Nucl. Fusion 40, 1145 (2000).
31. B. B. Kadomtsev, Sov. J. Plasma Phys. 1, 389 (1976).

32. M. Murakami, M. J. D. Callen, and L. A. Berry, Nucl. Fusion 16, 437 (1976).

33. A. Janos, E. D. Fredrickson, K. M. McGuire, et al., J. Nucl. Mater. 196-198, 602 (1992).

34. G. Pautasso, S. Egorov, and Ch. Tichmann, J. Nucl. Mater. 290-293, 1045 (2002).

35. K. H. Finken, A. Krämer-Flecken, G. Mank, and S. S. Abdullqev, J. Nucl. Mater. 290-293, 1064 (2003).

36. S. von Goeler, W. Stodiek, and N. Sauthoff, Phys. Rev. Lett. 33, 1201 (1974).

37. B. Lipschultz, E. S. Marmar, M. M. Pickerell, et al., Nucl. Fusion 24, 977 (1984).

38. S. Neuhauser, J. Schneider, and R. Wunderlich, Nucl. Fusion 26, 1679 (1986).

39. F. Wagner et al., Phys. Rev. Lett. 49, 1408 (1982).

40. G. Grieger, H. Renner, and H. Wobig, Nucl. Fusion 25-35, 1231 (1985).

41. H. Renner, J. Boscary, V. Erckmann, et al., Nucl. Fusion 40, 1083 (2000).

42. D. P. Ivanov, Nucl. Fusion 40, 1245 (2000).

43. M. Fujiwara et al., Nucl. Fusion 40, 1145 (2000).

44. B. J. Peterson et al., Nucl. Fusion 41, 519 (2001).

45. B. J. Peterson et al., J. Nucl. Mater. 290-293, 930 (2001).

46. D. Lawson, Proc. Phys. Soc. B 70, 6 (1957).

47. D. M. Meade, Nucl. Fusion 14, 289 (1974).

48. R. Behrisch and V. Prozesky, Nucl. Fusion 30, 2166 (1990).

49. G. Wolf, D. Reiter, and H. Klever, Nucl. Fusion 30, 2150 (1990).

50. H. M. Redi and S. A. Cohen, J. Nucl. Mater. 176177, 2623 (1990).

51. D. Reiter, H. Klever, G. H. Wolf, et al., Plasma Phys. Control. Fusion 33, 1579 (1991).

52. R. Behrisch, Nucl. Fusion, Suppl., p. 1 (1991).

53. D. Naujoks, Plasma Material Interaction in Controlled Fusion (Springer, Berlin, Heidelberg New York, 2006).

54. I. Langmuir, Phys. Rev. 33, 945 (1929).

55. R. Chodura, Physics of Plasma-Wall Interactions in Controlled Fusion, NATO ASI Ser. B: Physics, Vol. 113, p. 99 (Plenum, New York, London, 1984).

56. J. L. Crastron, R. Hancox, A. E. Robson, et al., in Proc. of the 2nd Intern. Conf. on Atom. Energy (1958), p. 3214 .

57. V. A. Simonov, B. N. Shvilkin, and C. P. Katukov, Nucl. Fusion, Suppl., 325 (1962).

58. Ph. Staib and G. Staudenmaier, J. Nucl. Mater. 63, 37 (1976).

59. Ph. Staib and G. Staudenmaier, J. Nucl. Mater. 7677, 405 (1978).

60. G. M. McCracken and D. H. Goodall, Nucl. Fusion 18, 537 (1978).

61. K. Ertl and B. Juettner, Nucl. Fusion 25, 500 (1985).

62. R. Behrisch, Physics of Plasma-Wall Interactions in Controlled Fusion, NATO ASI Ser. B: Physics, Vol. 113, p. 495 (Plenum, New York, London, 1984).

63. B. Juttner, Beitr. Plasmaphys. 19, 25 (1979). 
64. M. G. Drouet, Jpn. J. Appl. Phys. 20, 229 (1981).

65. R. Behrisch, Contrib. Plasma Phys. 42, 431 (2002).

66. C. Garcia-Rosales, R. Behrisch, B. Juttner, et al., in Proc. of the 21st EPS Conf. on Controlled Fusion and Plasma Physics (Montpellier, 1994), p. 718.

67. R. Behrisch, M. Mayer, and C. Garcia-Rosales, J. Nucl. Mater. 233-237, 673 (1996).

68. H. Esser, V. Philips, P. Wienhold, et al., J. Nucl. Mater. 363-365, 146 (2007).

69. P. H. Rebut, R. J. Bickerton, and B. E. Klein, Nucl. Fusion 25, 1011 (1985).

70. J. Linke et al., Fusion Sci. Technol. 46, 124 (2004).

71. R. Behrisch and G. Venus, J. Nucl. Mater. 202, 1 (1993).

72. H. W. Carslaw and J. C. Jaeger, Conduction of Heat in Solids (Clarendon, Oxford, 1959).

73. H. F. Göldner, Leitfaden Der Technischen Mechannik (VEB Fachbuchverlag, Leipzig, 1989).

74. Touloukian, R. W. Powell, C. Y. Ho, and P. G. Klemens, Thermal Conductivity of Metallic Elements. Thermal Properties of Matter 1 (Plenum, New York, Washington, 1970).

75. C. García-Rosales and M. Balden, J. Nucl. Mater. 290-293, 173 (2001).

76. N. Yoshida, H. Iwakiri, K. Tokunaga, and T. Baba, J. Nucl. Mater. 337-338, 946 (2005).

77. K. Tunaga, R. P. Doerner, R. Seraydarian, et al., J. Nucl. Mater. 313-316, 92 (2003).

78. M. Tokitani, M. Miyamoto, K. Tokunaga, et al., J. Nucl. Mater. 363-365, 443 (2007).

79. R. Behrisch, J. Nucl. Mater. 93-94, 498 (1980).

80. J. L. Cecchi, S. A. Cohen, H. F. Dylla, and D. E. Post, J. Nucl. Mater. 121, 1 (1984).

81. V. Kotov, A. Litnovsky, A. S. Kukushkin, et al., J. Nucl. Mater. 390-391, 528 (2009).

82. R. Behrisch, G. Federici, and A. S. Kukushkin, J. Nucl. Mater. 313-316, 588 (2003).

83. V. Kotov, D. Reiter, A. S. Kukushkin, and H. D. Pacher, Phys. Scr. 136, 20 (2009).
84. W. Eckstein, Reflection Max Plank Inst. Report IPP 17/122 (Garching, 2009).

85. O. V. Ogorodnikova, J. Nucl. Mater. 313-316, 417 (2003).

86. S. Lindig, M. Balden, V. Kh. Alimov, et al., Physica Scr. 136, 100 (2009).

87. N. Yoshjda and H. Iwakiri, J. Nucl. Mater. 337-339, 946 (2005).

88. M. Tokotami, M. Miyamoto, K. Tokunaga, et al., J. Nucl. Mater. 363-365, 443 (2007).

89. N. W. Pleshivtsev, Cathode Pulverization (Atomisdat, Moscow, 1968) [in Russian].

90. Sputtering by Particle Bombardment I, Ed. by R. Behrish (Springer, Berlin, 1981).

91. Sputtering by Particle Bombardment II, Ed. by R. Behrish (Springer, Berlin, 1983).

92. Sputtering by Particle Bombardment III, Ed. by R. Behrish and K. Wittmaack (Springer, Berlin, 1991).

93. Sputtering by Particle Bombardment. Experiments and Computer Calculations from Treshold to MeV Energies, Ed. by R. Behrish and W. Ecktein (Springer, Berlin, 2006).

94. C. Garcia-Rosales, J. Nucl. Mater. 211, 202 (1994).

95. J. Roth, A. Kirschner, W. Bohmeyer, et al., J. Nucl. Mater. 337-339, 970 (2005).

96. R. Behrisch, V. Kripunov, R. T. Santoro, and J. M. Yesiil, J. Nucl. Mater. 285-263, 686 (1998).

97. J. Winter, J. Nucl. Mater. 145-157, 131 (1989).

98. Ch. Linsmeier, J. Luthin, and P. Goldstraß, J. Nucl. Mater. 290-293, 25 (2001).

99. W. Eckstein, Nucl. Instrum. Methods Phys. Res. B 171, 435 (2000).

100. V. I. Pistunoivich, A. C. Vertkov, Fv. A. Evtikhin, et al., J. Nucl. Mater. 233-237, 650 (1996).

101. B. J. Kripunov, V. P. Petrov, V. V. Shapkin, et al., J. Nucl. Mater. 313-316, 619 (2003).

102. S. Mirnov, J. Nucl. Mater. 390-391, 816 (2009).

103. R. Bastasz and W. Eckstein, J. Nucl. Mater. 290-293, 19 (2001). 